\title{
AVALIAÇÃO DE DESEMPENHO DOCENTE, DISCENTE E DE RESULTADOS M NA DISCIPLINA ADMINISTRAÇÃO EM ENFERMAGEM NAS ESCOLAS DE ENFERMAGEM NO BRASIL
}

\author{
TEACHING STAFF, STUDENT, AND ACHIEVEMENT EVALUATION \\ IN NURSING ADMINISTRATION COURSES \\ AT NURSING SCHOOLS IN BRAZIL
}

\section{EVALUCION DEL DESEMPENO DOCENTE, DICENTE Y DE RESULTADOS DEL CURSO DE ADMINISTRACIÓN EN ENFERMERÍA EN LAS ESCUELAS DE ENFERMERÍA DE BRASIL}

\author{
Paulina Kurcgant* \\ Maria Helena Trench Ciampone** \\ Vanda Elisa Andres Felli***
}

Kurcgant P, Ciampone MHT, Felli VEA. Avaliação de desempenho docente, discente e de resultados na disciplina Administração em Enfermagem nas escolas de enfermagem do Brasil. Rev Esc Enferm USP 2001; 35(4): 374-80.

\begin{abstract}
RESUMO
No presente trabalho os objetivos foram: analisar os referenciais teóricos relativos ao processo de avaliação de desempenho, buscando suas correlações com as diferentes correntes pedagógicas. Esses referenciais constituem as bases de análise dos dados que estão sendo coletados e trabalhados. O presente estudo está inserido em um projeto mais amplo, que vem sendo desenvolvido e que objetiva conhecer como se dá a avaliação docente, discente e de resultados nas disciplinas que tratam de conteúdos referentes à Administração em Enfermagem no âmbito dos cursos de Graduação e de Pós-Graduação no Brasil. Assim, espera-se contribuir para a explicitação e compreensão dessa realidade concreta, do processo de avaliação de desempenho, tendo em vista a transformação do ensino dessas disciplinas.
\end{abstract}

PALAVRAS-CHAVE: Avaliação de desempenho docente. Avaliação de desempenho discente. Avaliação de resultados. Ensino. Administração em Enfermagem.

\begin{abstract}
The objective of this study was to analyze the theoretical references related to the performance evaluation process, establishing their correlation to different pedagogical lines. These references constitute the foundation for the analysis of data being collected and studied. This study is part of a broader project, currently in progress, whose objective is to determine how to evaluate teachers, students and achievement in courses dealing with content related to Nursing Administration at the graduate and undergraduate levels in Brazil. We hope to be contributing to a clearer and better understanding of this concrete reality, and of the performance evaluation process in light of the changes in the teaching of such courses.
\end{abstract}

KEYWORDS: Evaluation of teaching staff performance. Evaluation of student performance. Evaluation of achievement. Teaching. Nursing Administration.

\section{RESUMEN}

En este trabajo los objetivos fueron analizar los referenciales teóricos relativos al proceso de evaluación de desempeno, buscando sus correlaciones com las diferentes corrientes pedagógicas. Esos referenciales constituyen las bases del análisis de los Jatos que están siendo recolectados y trabajados. El presente estudio está inserto en um proyecto más amplio, que se viene desarrollando y que objetiva conocer como se de la evalución docente, docente y de resultados en los cursos que tratan de los contenidos referentes a la Administración en Enfermería rn rl ámbito del plan de estudios de la carrera de Enfermeria, en los niveles de Pret-Grado y Pos-Grado, en Brasil. Así, se espera contribuir para la explicación y comprensión de esa realidad concetra, del proceso de evaluación de desempeno, teniendo en vista la tranformación de la enseñanza en las asignaturas que dictan esos contenidos.

PALABRAS-CLAVE: Evaluación de desempeno docente. Evaluación de desempeno dicente. Evaluación de resultados. Enseñanza. Administración en Enfermería.

\footnotetext{
* Enfermeira, Professora Titular junto ao Departamento de Orientação Profissional da Escola de Enfermagem da USP. Enfermeira, Professora Livre-Docente junto ao Departamento de Orientação Profissional da Escola de Enfermagem da USE

*** Enferneira, Professora Doutora junto ao Departamento de Orientação Profissional da Escola de Enfermagem da USE
} 


\section{INTRODUÇÃO}

Considerando a avaliação do ensino como atividade do cotidiano docente e vivenciando as dificuldades nesse exercício, as autoras consideram essencial conhecer, discutir e intercambiar propostas com outros docentes que vivenciam a realidade da área de ensino.

Pelo resgate do referencial teórico sobre avaliação, apreende-se que a avaliação seja ela discente, docente, de conteúdos programáticos, de estratégias didáticopedagógicas ou de programas ou cursos, o contexto em que se dá esse ensino é que dá o significado para a avaliação. Assim como a avaliação não pode ser analisada independentemente do ensino que avalia., o ensino tem que ser reconhecido e avaliado, à luz da realidade político-social que o abarca.

Analisando a contextualização do ensino para o seu real entendimento considera a estrutura social com suas relações de classe e de poder; a condição da economia, o modelo de desenvolvimento vigente e o modelo administrativo-organizacional do sistema educacional como elementos a serem estudados., Considera também que "os exames, as notas, os certificados escolares, enquanto comprovantes do grau de conhecimento do aluno, desempenham um papel crucial no sistema de ensino" (" .

Discorrendo sobre as iniciativas e experiências de avaliação do ensino superior brasileiro, enfatizam aquelas desenvolvidas ao nivel das instituições e privilegiam a discussão do ensino de graduação. Ainda com esse enfoque chamam atenção para como tratar a demanda de alunos com desempenho mais fraco, enfatizando o processo avaliativo como dificil e árduo (2) .

A vivência profissional na docência permite considerar que o ensino acontece em um campo referencial mutante onde as politicas sócio-economicas, educacional e de saúde interagem entre si fortalecendo significados e paradigmas. Permite considerar também, que intrinsecamente ao conhecimento é atribuído um poder e que este ou aquele conhecimento legitimam este ou aquele poder ou interesse; que o conhecimento trabalhado no ensino traz embutido no seu significado aparente, idéias e valores que determinam práticas sociais; que o ensino, como missão primeira do docente permite a transformação da realidade pela ação reflexiva e coletiva dos profissionais que forma; que o conhecimento deve ser contemplado nas suas contradições, ambigüidades e contestação que provoca; que a teoria é um referencial analítico de explicação da realidade e que a educação visa o desenvolvimento da consciência crítica; que a articulação docência serviço permite a formação ético-política profissional, tendo na realidade a vivência da dimensão técnico específica.
Tendo por base esses pressupostos e paradigmas e acreditando que a avaliação de desempenho docente, discente e de resultados pode constituir um elemento importante do processo emancipatório, justifica-se a importância do presente estudo para o ensino da enfermagem no Brasil.

Entretanto, a responsabilidade da avaliação transcende a pessoa do aluno e do professor uma vez que os responsáveis pelos resultados da avaliação são todos aqueles que participam, direta ou indiretamente, da implementação do ensino, em todos os níveis da estrutura institucional.

No âmbito da responsabilidade do Estado devem ser considerados problemas advindos da Política Educacional, em geral, e os específicos das instituições de ensino. No que diz respeito aos problemas da Politica Educacional destacam-se os relacionados à definição da política em si e os relacionados aos recursos disponiveis para a sua execução.

Quanto às dificuldades no âmbito das instituições, estas envolvem aspectos referentes às atitudes dos atores, implementação e realização do processo avaliativo e uso dos resultados.

Quanto ao primeiro aspecto apontado, atitude dos atores, considera que essas atitudes podem ser influenciadas pela visão de mundo dos sujeitos envolvidos, pelos interesses, valores, habilidades, etc 13). Quanto às variáveis que interferem no processo avaliativo dentre as variáveis ligadas ao contexto, isto é, correlacionadas às condições externas que influenciam, direta ou indiretamente a interação professor-aluno, incluem-se tanto as condições sociais e econômicas da comunidade, como também as condições estruturais da própria escola.

Ainda no referente às instituições e às politicas educacionais adotadas, deve ser considerado o planejamento educacional nos seus elementos constituintes.

O planejamento deve considerar a realidade, a definição de objetivos claros e significativos, os meios e recursos disponíveis, viáveis e possíveis, o estabelecimento de critérios e de princípios da avaliação para o planejamento e execução de todo o processo educacional. "Planejar, portanto, é pensar sobre aquilo que existe, sobre o que se quer alcançar, com que meios se pretende agir e como avaliar o que se pretende atingir" (4).

Vale explicitar que o planejamento educacional não pode ser confundido com a planificação das atividades didáticas de uma instituição. No entanto, os planos das disciplinas elaborados pelos docentes na Instituição guardam uma relação com o planejamento educacional, uma vez que é através das 
Instituições que o processo educacional age diretamente sobre os individuos.

Considerando o processo avaliativo nos seus elementos constitutivos e determinantes, pretende-se no presente estudo: correlacionar a avaliação docente, discente e de resultados do ensino das disciplinas de Administração em Enfermagem com as principais tendências pedagógicas.

\section{METODOLOGIA}

Partindo das concepções descritas (5) há uma relação dialética entre teoria e realidade empírica que se expressa no fato de que a realidade, informa a teoria que por sua vez a antecede. Dessa forma, a teoria contribui para a percepção da realidade num processo sem fim de distanciamento e aproximação. A teoria domina a construção do conhecimento através de conceitos gerais provenientes do momento anterior. Seu aprofundamento, de forma critica, permite desvendar dimensões não pensadas à respeito da realidade que não é evidente e que não se dá. Ela se revela à partir de interrogações elaboradas no processo de construção teórica.

Considera também, que toda construção teórica é um sistema cujas vigas mestras estão representadas pelos conceitos. Assim, os conceitos são as unidades de significação que definem a forma e o conteúdo de uma teoria. São um caminho de ordenação da realidade, de olhar os fatos e as relações, e ao mesmo tempo um caminho de criação.

Neste estudo optou-se pelo reconhecimento do processo de avaliação a partir do referencial teórico conforme diferentes abordagens pedagógicas, no sentido de desvendar as práticas do processo avaliativo, buscando uma verdadeira práxis.

Para tanto, segundo autores que estudam o tema avaliação de desempenho, partiu-se do reconhecimento dos diferentes elementos constitutivos do processo avaliativo, no âmbito do ensino, privilegiando a avaliação docente, discente e de resultados.

Este estudo, faz parte de um projeto mais amplo, cujo objetivo geral é identificar as vertentes conceituais, métodos e técnicas que embasam a avaliação de desempenho docente, discente e de resultados nas disciplinas de Administração em Enfermagem, nas doze Instituições de Ensino Superior de Enfermagem do Brasil, que ministram o ensino no âmbito de Graduação e Pós-Graduação.

$\mathrm{Na}$ atual etapa de investigação buscou-se identificar as diferentes tendências pedagógicas e suas implicações nos processos de avaliação docente, discente e de resultados.

\section{O REFERENCIAL TEÓRICO DE ANÁLISE}

O referencial de análise pautou-se na proposta (6-8), que consideram que o contexto histórico educacional pode ser resgatado segundo as diferentes tendências pedagógicas, ou seja: tradicional, comportamentalista, humanista, cognitivista e sóciocultural.

Segundo esses autores, na abordagem tradicional, o professor centraliza o processo, organiza e controla as decisões e as ações didáticas. Para trabalhar os conteúdos, como recursos pedagógicos, o professor se apoia no livro didático, no giz, na lousa, etc. Nesse enfoque o professor é o principal canal de mediação do processo ensino aprendizagem, cabendo ao aluno a automatização e memorização dos conteúdos.

Nessa corrente a avaliação discente dá-se pela atribuição de notas aos alunos mediante seu nivel de desempenho nas provas e exames. Tem como finalidade classificar e selecionar os alunos com condições de prosseguir nos estudos. Os princípios que orientam essa tendência de avaliação são a inflexibilidade e a imparcialidade. Para tanto, o professor é o responsável pela determinação das estratégias de avaliação, sendo que as ,mais adotadas são a argüição oral, trabalhos práticos e provas.

$\mathrm{Na}$ corrente comportamentalista acredita-se que o homem é produto do meio ambiente e que este pode exercer controle e manipulação desse meio. Assim, pressupõe-se, também, que o mesmo pode ocorrer com o processo educacional. O elemento -principal nessa corrente é a organização racional dos meios, sendo o professor o executor do processo educacional e as tecnologias adotadas têm a finalidade de reforçar e manter os comportamentos desejados. A instrução programada, bem como a técnica de demonstração, pelo fato de fragmentarem os conteúdos programáticos de forma a obter complexidade crescente, reforçam os comportamentos desejados em cada etapa da aprendizagem.

Nessa perspectiva, a avaliação mede de forma quantificável o rendimento apresentado pelo aluno em exercícios e exames. O aluno é classificado segundo essa escala de rendimento e assim, decide-se aqueles que devem ou não prosseguir. O elemento principal nessa corrente é a objetividade e as estratégias de avaliação adotadas pelo professor são os exercícios e provas.

Quanto à abordagem humanista enfatiza-se as relações interpessoais, cabendo ao professor o papel de facilitador da aprendizagem buscando atender as necessidades e expectativas dos alunos e criando condições para que os alunos aprendam. Nessa 
proposta os recursos e meios utilizados têm pouca importância. As tecnologias devem permitir a participação e o diálogo professor-aluno.

A avaliação consiste no procedimento de julgar o aproveitamento do aluno quanto ao seu grau de satisfatoriedade no processo em curso. A avaliação visa aferir o grau de aproveitamento e satisfação do aluno, tendo em vista a sua promoção para a etapa seguinte.

Quanto aos principios orientadores dessa vertente, estão a continuidade, a compatibilidade com o trabalho desenvolvido e a compreensão. Quanto às estratégias, são adotados, entre outros instrumentos, provas e exames.

$\mathrm{Na}$ abordagem cognitivista, enfatiza-se a forma como os alunos lidam com os estímulos ambientais, organizam dados, sentem e resolvem problemas, adquirem conceitos e empregam símbolos. Pauta-se em estratégias interacionistas, de trabalho em equipe, promovendo a socialização do aluno e permitindo o compartilhamento de idéias, informações, responsabilidades e decisões. Os jogos são buscados como recursos didáticos por acreditar-se que estes possibilitam ao aluno vivenciar uma atividade cooperativa, desenvolvendo a capacidade de exercer ações colaborativas.

A avaliação da aprendizagem busca apreender até que ponto foram atingidos os objetivos educacionais. Tem como finalidade, fornecer dados para orientar a reformulação do planejamento curricular e também para apoiar decisões quanto à promoção dos alunos. Os princípios orientadores dessa corrente são continuidade, amplitude e compatibilidade com os objetivos propostos. As estratégias de avaliação adotadas baseiam-se em instrumentos elaborados pelo professor.

Quanto a abordagem sócio cultural esta visualiza o homem como sujeito inserido em um contexto sócioeconômico- político e cultural, e portanto partícipe do processo de construção e de intervenção sobre o mesmo para a sua transformação. Assim, nessa concepção, o diálogo é elemento essencial porque permite ao aluno conhecer o mundo, a natureza, as relações sociais, incluindo as contradições e os conflitos $\left({ }^{\prime}\right.$. Segundo essa proposta cabe ao professor promover condições para que o aluno desenvolva a consciência da realidade, identificando as ideologias, as relações de poder e intencionalidade, considerando a linguagem e a cultura. Pauta-se em estratégias como a problematização de situações, buscando apreender o que o aluno já conhece sobre a situação problema e o que deve ainda ser aprendido. O professor vai dessa forma estimulando os alunos a formularem os objetivos de aprendizagem, no sentido de, na situação, construir alternativas de intervenção na realidade. $\mathrm{O}$ processo ensino aprendizagem baseia-se na facilitação da aprendizagem e os alunos são sujeitos ativos do mesmo.

A avaliação da aprendizagem baseia-se na capacidade do aluno apreender criticamente a realidade vivenciada e ser capaz de interagir e intervir nessa realidade transformando-a. As estratégias de avaliação são elaboradas pelos próprios alunos constando de planos de intervenção e transformação da realidade, estimulando a auto-avaliação.

$\mathrm{Na}$ década de noventa, surge um nove modelo pedagógico denominado de "Empowerment" que ocorre num contexto onde a experiência do conhecimento deve ser interativa. Nessa corrente busca-se o empoderamento das pessoas para a ação, através do desenvolvimento de habilidades e contribuições significativas ao processo ensino-aprendizagem. A novidade, o novo, bem como, o inovar, são os elementos que embasam as propostas pedagógicas e que direcionam as transformações da realidade. Nessa perspectiva os estudantes assumem o controle de seu próprio tempo, lugar e ritmo de estudo, bem como, da seqüência e do material a ser estudado. Espera-se que estes sejam capazes de comunicarem-se, livremente, com colegas e professores. O pressupostos dessa abordagem baseiam-se na perspectiva do homem como sendo responsável e potencial agente de transformação, norteando suas ações pela ética do coletivo e da cidadania.

Essa proposta coincide com o desenvolvimento de tecnologias instrucionais, que permitem estruturar o ensino com momentos presenciais e de ensino à distância mediado pela possibilidade da comunicação virtual entre docentes e discentes. As estratégias de avaliação nesse processo são ainda incipientes, destacando-se na enfermagem, o trabalho elaborado denominado "Tecnologias educacionais: possibilidades e dificuldades no ensino de Administração em Enfermagem" (8).

Quanto à avaliação docente, no âmbito do ensino de terceiro grau, um estudo realizado (10), constata que "a estrutura departamental nas Unidades de Ensino, favorece o desenvolvimento de ações individuais voltadas para dentro da própria Universidade. O ensino não tem fugido muito da tradição de reprodução do conhecimento.. Na verdade, quanto mais qualificado um docente, mais ele tende a se afastar da sala de aula, especialmente da graduação, para dedicar-se à pós-graduação e à pesquisa".

Esta percepção de avaliação docente é coincidente com as propostas tradicionais de avaliação discente em consonância com as correntes pedagógicas tradicional e comportamentalista. Nestas, o instrumento de avaliação docente é pré-determinado 
pelas instâncias superiores, o que caracteriza uma dissociação entre planejamento, execução e avaliação do processo educacional, reproduzindo a proposta taylorista no ensino.

Em pesquisa realizada sobre o ensino da disciplina de administração em enfermagem em cursos de graduação da grande São Paulo, conclui que apesar de algumas escolas terem os seus objetivos e conteúdos programáticos voltados para uma dimensão prospectiva do processo avaliativo que instrumentaliza o discente para atuar na realidade contemporânea, estas mantém, como as outras, modelos conservadores de avaliação do processo ensino-aprendizagem (11).

Em estudo sobre avaliação do processo ensinoaprendizagem do aluno, faz importante retrospectiva histórica da avaliação educacional na legislação da educação mostrando que muito embora tenham sido alterados, ao longo do tempo, os conceitos de avaliação, o entendimento da finalidade desta, dos princípios norteadores e da realização do processo, a responsabilidade sobre o processo é atribuída somente à figura do professor (3). Isso contraria a premissa de que os responsáveis pelos resultados da avaliação são todos aqueles que participam, direta ou indiretamente, da implementação do ensino, em todos os níveis da estrutura institucional, isto é, Estado, Instituição educativa, professores e alunos.

A avaliação dos programas de pós-graduação tem incentivado os docentes a realizarem atividades específicas deste âmbito de atuação com ênfase nas atividades de pesquisa e de divulgação do conhecimento produzido.

Esta idéia é referendada (10) quando considera que não basta ser "bom pesquisador para ser, automaticamente, bom professor".

Também nos processos de avaliação docente e nos planos de carreira raramente são explicitados os critérios valorativos do desempenho docente no âmbito da graduação como forma de ascensão na carreira.

Um dos desafios para a avaliação de resultados do ensino, diz respeito à indissociabilidade entre atividades docentes no ensino, na pesquisa e na extensão no âmbito das Universidades.

Nessa direção (3) já apontava para o princípio de unidade de pesquisa e de ensino, por iniciativa dos estudantes, dos professores e da instituição como sendo rico de conseqüências. Para o autor, somente o pesquisador pode, verdadeiramente, ensinar. Complementa dizendo que qualquer outro que dissociar o ensino da pesquisa, limita-se a transmitir um pensamento inerte.

Ainda em 1989, o Relatório do VIII Congresso da Associação Nacional dos Docentes de Ensino
Superior -ANDES- com base nos debates sobre a constituinte, já reforçava as propostas de indissociabilidade entre ensino, pesquisa e extensão.

O texto Constitucional consagra esse princípio em seu art. 207 "as Universidades gozam de autonomia didático-científica, administrativa e de gestão financeira, obedecendo ao princípio da indissociabilidade entre ensino, pesquisa e extensão".

Embora reconhecendo a importância incontestável desse princípio, na prática, a avaliação de desempenho docente em uma área específica, no caso o ensino, tem se revelado desafiadora.

Assim formas de avaliação docente têm sido adotadas ainda que de forma incipiente, pelas Universidades Públicas. A avaliação docente realizada pelos discentes ao longo de uma disciplina ministrada, bem como pela chefia imediata, tem sido uma prática recente e limitada a alguns contextos.

Dessa forma, a avaliação docente, como proposta efetiva de avaliação, ainda é uma prática em construção reforçando que se deve vislumbrar como horizonte as abordagens pedagógicas emancipatórias, participativas, que promovam o empoderamento dos indivíduos partícipes do processo coletivo.

Nessa direção de acordo com as tendências pedagógicas atuais, a avaliação docente estaria menos vinculada ao conhecimento do técnico específico e mais vinculada à dimensão ético-política. Entretanto os processos que privilegiam um dos âmbitos da atuação docente, seja o ensino, a pesquisa ou extensão, deve efetivamente criar parâmetros pautados em cada realidade, para avaliar aquele âmbito específico de atuação.

Em relação ao processo avaliativo de resultados, vários problemas técnicos devem ser considerados mas, o principal diz respeito à elaboração dos indicadores da avaliação.

Nessa direção, as propostas de ensino tradicionais apontam para dois tipos principais de avaliação: a formativa e a somativa.

A avaliação formativa ocorre durante o desenvolvimento do projeto ou curso a fim de intervir no processo em andamento. A avaliação somativa é feita no final do projeto ou curso, sendo que os resultados não interferem no processo em curso.

Nas propostas emancipatórias participativas a avaliação emancipatória contempla não só avaliar os conhecimentos (resultados), mas instrumentalizar e estimular o educando para uma apropriação crítica e ativa do conhecimento, bem como oportunizar espaços para que o docente e o discente exercitem o processo de auto-avaliação. Assim o empowerment refere-se a ambos os sujeitos partícipes do processo avaliativo para que juntos transformem a realidade de ensino. 
EXPLICITAÇÃO E COMPREENSÃO DA REALIDADE CONCRETA

Estudos realizados (1142) relacionados ao reconhecimento de como vem se dando o ensino das disciplinas referentes à Administração em Enfermagem , sendo o primeiro no âmbito da graduação e da pósgraduação e o segundo no âmbito da graduação, mostram que existem semelhanças e diferenças importantes na forma como esse ensino vem sendo ministrado .

Em estudo realizado, em oito Escolas de Enfermagem do Brasil, resgatou os objetivos, a carga horária, a duração, o momento de inserção da disciplina no curso, o conteúdo programático, as estratégias adotadas e a avaliação do ensino, conforme os planos de ensino das disciplinas ofertadas (3).

Os resultados encontrados apontaram para a necessidade de re-orientação desse ensino e de capacitação docente em consonância com as mudanças a serem implementadas em função das políticas de ensino e de saúde do país.

No que se refere especificamente à avaliação do ensino o estudo mostrou que as estratégias pedagógicas adotadas tendem a propostas pedagógicas tradicionais, com poucas experiências inovadoras que permitem a participação efetiva do estudante. Resgata também, que alguns conteúdos avançam no sentido de abordar relações sociais e profissionais mais igualitárias, enquanto outros, situam-se em abordagens mais tradicionais do gerenciamento.

Quanto à avaliação discente e de resultados do processo ensino-aprendizagem, há forte coincidência entre os métodos e técnicas de avaliação apontados nos planos de ensino. Estas técnicas encontram-se ancoradas em abordagens pedagógicas tradicionais e comportamentalistas, sendo, as mais citadas, as provas escritas, execução de trabalhos escritos e a avaliação de desempenho do aluno no campo de prática, nos diferentes cursos de graduação.

A avaliação do ensino nos cursos de pósgraduação avançam um pouco mais na direção das abordagens humanistica e sociocultural, com a apresentação de seminários, estudos de casos e grupos de discussão.

O estudo desenvolvido em dez Escolas de Enfermagem da Grande São ( Paulo, também mostra que os modelos tradicionais de avaliação são predominantes nessa escolas. A prova escrita, o trabalho escrito, prova oral e apresentação oral de trabalhos referidos nos planos de ensino, referendam o modelo tradicional de avaliação ${ }^{(11)}$.

A autora refere ainda que apenas três das escolas apresentam formas diferenciadas de avaliação como participação em sala de aula e avaliação de desempenho. Conclui que apesar de algumas escolas estarem voltadas nos seus conteúdos programáticos para uma dimensão prospectiva que visa instrumentalizar o discente para atuar na realidade contemporânea, mantém como as outras escolas, formas conservadoras de avaliação do processo ensinoaprendizagem.

Em estudo (8), avança no sentido de construir uma reflexão em torno do uso das tecnologias educacionais no ensino da disciplina de Administração em Enfermagem, discutindo a sua inserção no processo educacional dessa disciplina. Segundo a autora, " reconhecer os preconceitos acerca dessas tecnologias, implicou em encontrar no cotidiano da docência, um sentido para as antigas estratégias educacionais, um "para que", tendo como referência a idéia de criação, de dar à luz às velhas formas de ensinar."

A autora considera ainda, que as estratégias por ela denominadas de tecnologias de ensino, avançam em direção a um projeto pedagógico sociocultural, por comprometer-se a trabalhar o pensar e a construção do conhecimento num campo onde as estratégias de ensino, em suas mais diferentes formas, são aplicadas para propiciar novos modos de ensino.

Essas novas tecnologias, aliadas ao desenvolvimento do pensamento critico, poderá catalisar a transformação do perfil do profissional a ser formado, no referente ao gerenciamento, para intervir criticamente na realidade empírica. Para tanto não basta apenas a introdução de novas tecnologias de ensino e de avaliação da aprendizagem, cabendo ao professor atuar como facilitador da aprendizagem fundamentada na análise crítica da realidade.

A aprendizagem fundamentada na análise critica e na reflexão requer a tomada de consciência sobre a realidade na qual está inserido o aprendiz (14) A autora retoma, que "a tomada de consciência frente ao mundo só ocorre mediante o enfrentamento com a realidade concreta.(..) A partir das relações do homem com a realidade, resultantes de estar com ela e de estar nela, pelos atos de criação, recriação e decisão, vai ele dinamizando o seu mundo. Vai humanizando a realidade e se humanizando, na medida que acrescenta, a ela, algo de que ele mesmo é fazedor" (13).

Concluindo, como nós também cremos que "a educação é um ato político e só terá significado, se for, também, um ato de amor. E será um ato de amor à medida em que o professor tenha a coragem de ousar desenvolvendo junto com seus alunos uma educação libertadora, embasada no diálogo aberto, na relação 
horizontal, na crença nas potencialidades dos alunos e na concessão do direito de participação dos mesmos na gerência de seu destino acadêmico."

Retomamos os objetivos propostos para o presente estudo acreditando que a explicitação das correlações existentes entre o processo avaliativo e as diferentes correntes pedagógicas possam subsidiar

\section{REFERÊNCIAS BIBLIOGRÁFICAS}

(1) Martins J, Espósito VHC. Um enfoque fenomenológico do currículo: educação como poíeses. São Paulo: Cortez; 1992.

(2) Ribeiro ERD, Schwartzman S, organizadores. Avaliação do ensino superior. São Paulo: EDUSP; 1992.

(3) Santos JBG. Avaliação emancipatória: uma alternativa para a facilitação da aprendizagem na disciplina Enfermagem em Centro Cirúrgico.[dissertação]. Ribeirão Preto (SP): Escola de Enfermagem de Ribeirão Preto/USP; 1996.

(4) Menegolla M, Sant'anna IM. Por que planejar? Como planejar? 5 ${ }^{\mathrm{a}}$ ed. Rio de Janeiro: Vozes; 1997.

(5) Minayo MCS. O desafio do conhecimento: pesquisa qualitativa em saúde. São Paulo: Hucitec; 1993.

(6) Mizukami MGN. Ensino: as abordagens do processo. São Paulo: EPU; 1986.

(7) Moraes MC. O paradigma educacional emergente. $3^{\mathrm{a}}$ ed. Campinas: Papirus; 1999.

(8) Leite MMJ. Tecnologias educacicnais: possibilidades e dificuldades no ensino de administração em enfermagem. [livre- docência]. São Paulo (SP): Escola de Enfermagem da USP; 2000.

(9) Freire P- Pedagogia: diálogo e conflito. São Paulo: Cortez; 1986.

(10) Mazzili S. A pedagogia além do discurso.

Piracicaba: UNIMEP; 1994. a reflexão acerca dos desafios que envolvem a atuação docente e discente no processo de ensino-aprendizagem. Possam ainda, constituir um estímulo para que o efeito dessa reflexão reverta em práticas educacionais emancipatórias onde os instituintes sejam mais efetivos na transformação do instituído aqui explicitado.

(11) Nimtz MA. O ensino da disciplina de Administração em Enfermagem nas escolas de graduação da grande São Paulo. [dissertação]. São Paulo (SP): Escola de Enfermagem da USP; 1999.

(12) Kurcgant P. 0 ensino de administração em enfermagem nas Escolas de Enfermagem do Brasil e as políticas de ensino e de educação. [Relatório de pesquisa-CNPq]. São Paulo: EE/USP; 1999.

(13) Freire P Educação como prática da liberdade. $21^{4}$ ed. Rio de Janeiro: Paz e Terra; 1992.

(14) Santos BSS. Pela mão de Alice: o social e o político na pós- maternidade $2^{\mathrm{a}}$ ed. São Paulo> Cortez; 1996

\section{Artigo recebido em $26110 / 00$}

\section{Artigo aprovado em 19/07/02}

